\title{
Phenolic Characterization and Geographical Classification of Commercial Extra Virgin Olive Oils Produced in Turkey
}

\author{
Derya Alkan · Figen Tokatli $\cdot$ Banu Ozen
}

Received: 4 May 2011/Revised: 23 June 2011/ Accepted: 27 July 2011/Published online: 10 August 2011

(c) AOCS 2011

\begin{abstract}
The aim of this research was to characterize the extra virgin olive oil samples from different locations in the Aegean coastal area of Turkey in terms of their phenolic compositions for two consecutive years to show the classification of oil samples with respect to harvest year and geography. Forty seven commercial olive oil samples were analyzed with HPLC-DAD, and 17 phenolic compounds were quantified. Hydroxytyrosol, tyrosol, vanillic acid, $p$-coumaric acid, ferulic acid, cinnamic acid, luteolin and apigenin were the characteristic phenols observed in all oil samples for two harvest years. Syringic acid, vanillin and $m$-coumaric acid were the phenolic compounds appeared in the olive oil depending on the harvest year. Partial least square-discriminant analysis (PLS-DA) of data revealed that oils from the north Aegean and south Aegean areas had different phenolic profiles. The phenolic compounds, which played significant roles in the discrimination of the olive oils, were tyrosol, oleuropein aglycon, cinnamic acid, apigenin and hydroxytyrosol to tyrosol ratio. The Aegean coastal region is the largest olive oil producer and exporter of Turkey. This study shows that the olive oils from different parts of the region have their own defining characteristics that can be used in the authentication studies and geographical labeling of Turkish olive oils.
\end{abstract}

Keywords Olive oil · Phenolic composition . Geographical origin · Harvest year

D. Alkan · F. Tokatli $(\bowtie) \cdot$ B. Ozen

Izmir Institute of Technology, Department of Food Engineering,

35430, Urla, Izmir, Turkey

e-mail: figentokatli@iyte.edu.tr

\section{Introduction}

Phenolic compounds of olive oil have been of major interest to researchers due to their positive effects for both human health and olive oil itself. Tuck and Hayball [1] reviewed the metabolism and health effects of major phenolic compounds in olive oil. The anti-inflammatory effects of oleuropein glycoside and caffeic acid found in extra virgin olive oil were shown by Miles et al. [2]. Visioli et al. [3] and Perez-Jimenez et al. [4] reviewed the antioxidant biological activities of olive and olive oil phenols. Phenolic compounds are one of the main reasons for the rather high oxidative stability of the olive oil compared to other edible oils [5,6]. The phenolic composition of olive oil also affects the sensory properties of the product [7, 8]. Phenolic substances as the minor constituents of the olive oil are used in the characterization and authentication with respect to geographical origin and cultivars [9-12].

Turkey is a significant participator in olive oil production and trade. According to the statistics given by International Olive Council (http://www.internationaloliveoil.org, 2010), Turkey contributes $4.6 \%$ to the world's olive oil production and exported $8 \%$ on the average between the years 2004 and 2010. In 2008, the production was 130,000 tonnes and it increased to 160,000 tonnes in the 2010 harvest year. Meanwhile Turkey has become the second largest producer of table olives in the world with 390,000 tonnes after Spain. This was $18 \%$ of the World production in 2010 . All these figures show that Turkey is one of the leading countries in olive and olive oil production. Despite all this, relatively little information is available in the literature about the characteristics of Turkish olive oils, to the best of our knowledge. Most of the research is on the sensory properties, fatty acid profiles, total phenolic contents and other quality parameters such as peroxide and $K$ values [13-18]. However, there are few studies about the phenolic profiles [11, 19]. The characterization of 


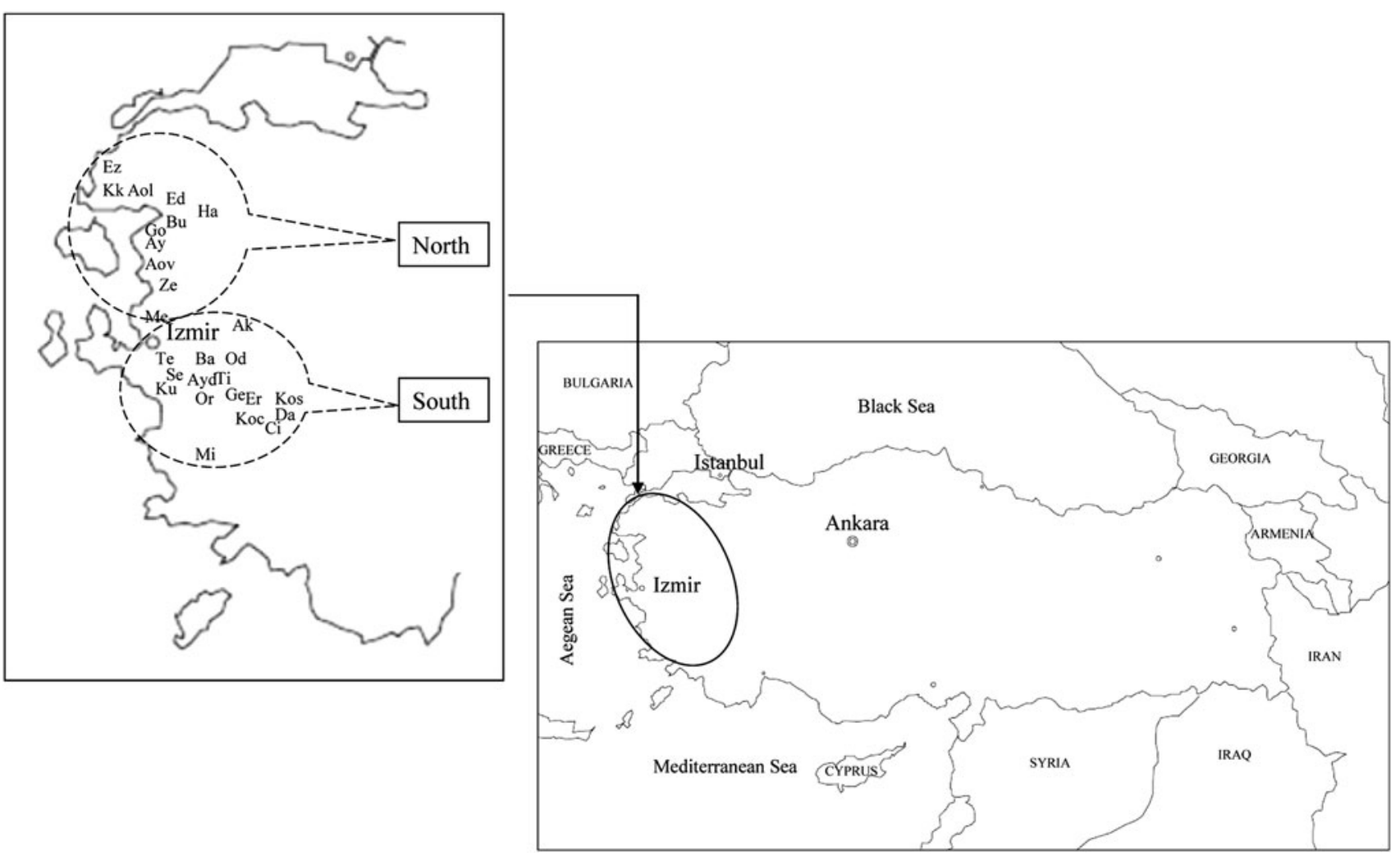

Fig. 1 Map showing the distribution of oil samples from the Aegean region of Turkey

food products is important in geographical labeling. Such known labels are the protected designation of origin (PDO) and the protected geographical indication (PGI) introduced first in 1992 with official European regulations. These designations guarantee that the quality of the product is associated with its geographical origin. Since the phenolic composition of olive oil is considered as a fingerprint, it can be used to characterize and classify the products from different regions and serve as a means for PDO and PGI labeling.

The aim of this study was to obtain the phenolic compositions of Turkish extra virgin olive oils produced in two different regions of Turkey and to show the differences between these olive oil groups. The northern and southern Aegean regions are the main producers of olive and olive oil in Turkey (Fig. 1). The extra virgin olive oil samples of 2005 and 2006 harvest years from these regions were used in this study. The phenolic profiles were utilized to differentiate the oils with respect to their geographical origin by analyzing data with multivariate statistical techniques.

\section{Material and Methods}

\section{Extra Virgin Olive Oil Samples}

Forty-seven olive oil samples, belonging to 27 different locations in the coastal Aegean Region, were kindly supplied by Taris Inc., which is the union of olive and olive oil co-operatives in the region. The samples came from two different areas (coastal south and coastal north) of the Aegean region of the Turkey (between 36-40 north parallels and 26-29 east meridians) for two successive harvest years (2005 and 2006). Usually the city of Izmir is defined as the mid-point between these two origins. Table 1 shows the olive oil samples used in the study for 2005 and 2006 harvest years. All olive oil samples have free fatty acidity in terms of $\%$ oleic acid between 0.22 and 0.86 except Menemen olive oil of year 2005, which has free fatty acid value of 1.20 (data not shown). As soon as they were received, the olive oil samples were transferred to dark bottles and stored at $9{ }^{\circ} \mathrm{C}$ and the headspaces were replaced by nitrogen prior to analyses.

\section{Chemicals}

The quantification of phenolic compositions were done by using the following phenolic standards: Gallic acid, hydroxytyrosol, 4-hydroxybenzoic acid, tyrosol, chlorogenic acid, 2,3 dihydroxybenzoic acid, 4-hydroxyphenylacetic acid, 3-hydroxyphenylacetic acid, vanillic acid, caffeic acid, syringic acid, vanillin, $p$-coumaric acid, ferulic acid, $m$-coumaric acid, o-coumaric acid, oleuropein, cinnamic acid, luteolin and apigenin. Hydroxytyrosol and oleuropein 
Table 1 Commercial EVOO samples

\begin{tabular}{|c|c|c|c|}
\hline North (N) & $\begin{array}{l}\text { Sample } \\
\text { codes }\end{array}$ & South (S) & $\begin{array}{l}\text { Sample } \\
\text { codes }\end{array}$ \\
\hline \multicolumn{4}{|l|}{2005} \\
\hline Ezine & $\mathrm{Ez}$ & Akhisar & Ak \\
\hline Ezine-Organic & Ez-or & Menemen & $\mathrm{Me}$ \\
\hline Kucukkuyu & $\mathrm{Kk}$ & Tepekoy & $\mathrm{Te}$ \\
\hline Altinoluk & Aol & Bayindir & $\mathrm{Ba}$ \\
\hline Altinoluk-sulubaski & Aol-su & Selcuk & $\mathrm{Se}$ \\
\hline Edremit & $\mathrm{Ed}$ & Aydin & Ayd \\
\hline Havran & $\mathrm{Ha}$ & Ortaklar & Or \\
\hline Burhaniye & $\mathrm{Bu}$ & Kocarli & Koc \\
\hline Gomec & Go & Milas & $\mathrm{Mi}$ \\
\hline Ayvalik & Ay & & \\
\hline Altinova & Aov & & \\
\hline Zeytindag & $\mathrm{Ze}$ & & \\
\hline \multicolumn{4}{|l|}{2006} \\
\hline Ezine & $\mathrm{Ez}$ & Tepekoy & $\mathrm{Te}$ \\
\hline Kucukkuyu & $\mathrm{Kk}$ & Bayindir & $\mathrm{Ba}$ \\
\hline Altinoluk & Aol & Odemis & Od \\
\hline Edremit & $\mathrm{Ed}$ & Tire & $\mathrm{Ti}$ \\
\hline Havran & $\mathrm{Ha}$ & Selcuk & $\mathrm{Se}$ \\
\hline Burhaniye & $\mathrm{Bu}$ & Kusadasi & $\mathrm{Ku}$ \\
\hline Gomec & Go & Germencik & $\mathrm{Ge}$ \\
\hline Ayvalik & Ay & Aydin & Ayd \\
\hline Altinova & Aov & Ortaklar & Or \\
\hline \multirow[t]{6}{*}{ Zeytindag } & $\mathrm{Ze}$ & Kosk & Kos \\
\hline & & Dalama & $\mathrm{Da}$ \\
\hline & & Kocarli & Koc \\
\hline & & Erbeyli & Er \\
\hline & & Cine & $\mathrm{Ci}$ \\
\hline & & Milas & $\mathrm{Mi}$ \\
\hline
\end{tabular}

were purchased from Extrasynthese (Genay, France). All other chemical reagents were HPLC grade and from Sigma-Aldrich Chemie (Steinheim, Germany).

\section{Peroxide Value}

Peroxide values (PV) were determined according to the analytical method described in European Official Method of Analysis (Commission Regulation EEC N-2568/91) and expressed as mequiv $\mathrm{O}_{2} \mathrm{~kg}^{-1}$.

\section{Total Phenol Content}

The total phenol content (TPC) of the olive oil extracts were determined by the Folin-Ciocalteu spectrophotometric method at $765 \mathrm{~nm}$, in terms of gallic acid (mg GA/kg oil) [20]. The measurements were repeated three times.
Color

The oil color was expressed in terms of $\mathrm{L}^{*}, \mathrm{a}^{*}$, and $\mathrm{b}^{*}$ obtained by a colorimeter (Chromometer type CR-400, Minolta Sensing, Osaka, Japan). Color coordinates were measured following the white calibration (For illuminants $\mathrm{D}_{65}, Y=93.5, x=0.3140, y=0.3318$ ). Then $20 \mathrm{~mL}$ of olive oil sample was placed in the glass cell and the color of each sample was measured at three different positions. The oil color was reported as the average of three readings.

HPLC-DAD Analysis of the Phenolic Compounds

The phenolic extracts were obtained according to the procedure of Brenes et al. [21]. Briefly, a sample of olive oil $(14 \mathrm{~g})$ was extracted by using $4 \times 14 \mathrm{~mL}$ of methanol/ water $(80: 20 \mathrm{v} / \mathrm{v})$. Methanol was removed, and then $15 \mathrm{~mL}$ of acetonitrile was added to the residue and washed with $(3 \times 20 \mathrm{~mL})$ of hexane. The resulting acetonitrile solution was evaporated under vacuum and the residue was flushed with nitrogen and dissolved in $1 \mathrm{~mL}$ of methanol/water. The final extract was filtered through a $0.45-\mu \mathrm{m}$ pore-size membrane filter and transferred into a tube. The extract was immediately injected to HPLC as $20 \mu \mathrm{L}$. Gallic acid was used as the internal standard.

An HPLC system composed of a Perkin Elmer (PE) series 200 pump (Norwalk CT, USA), PE series 200 diode array detector, PE-Nelson 900 series interface, Meta Therm HPLC column heater (series no:9540, Torrance) and a $5 \mu \mathrm{m}, 25 \mathrm{~cm} \times 4.6 \mathrm{~mm}, \mathrm{C} 18$ column (Ace, Aberdeen, Scotland) was used to analyze phenolic compounds. Separation was achieved by gradient elution using an initial composition of $90 \%$ water with $0.2 \%$ acetic acid (A) and $10 \%$ methanol (B). The concentration of B was increased to $30 \%$ in $10 \mathrm{~min}$ and maintained for $20 \mathrm{~min}$. Subsequently, B percentage was raised to $40 \%$ in $10 \mathrm{~min}$, maintained for $5 \mathrm{~min}$, increased to $50 \%$ in $5 \mathrm{~min}$, and maintained another $5 \mathrm{~min}$. Finally, B was increased to 60 , 70 , and $100 \%$ in 5 min periods. Initial conditions were reached in $15 \mathrm{~min}$. The flow rate was $1 \mathrm{~mL} \mathrm{~min}^{-1}$. Column temperature was kept at $35{ }^{\circ} \mathrm{C}$. Chromatograms were obtained at 280 and $320 \mathrm{~nm}$ and different phenolic compounds were identified by comparing retention times with those of commercial standards. Phenolic compounds were quantified by using their respective 4-point calibration curves and expressed as $\mathrm{mg} \mathrm{kg}^{-1}$.

Statistical Analysis

Chemical data including TPC, PV, and color measurements were analyzed by analysis of variance (ANOVA) using Tukey's test at 5\% significance level in Minitab 14 statistical software (Minitab Inc., State College, USA). The 
multivariate data matrix $\mathbf{X}$ of size $(47 \times 23)$ represents 47 samples analyzed for two years, with 17 phenolic compounds, hydroxytyrosol to tyrosol ratio, TPC, and PV measurements, and 3 color parameters. The raw data were transformed into a suitable form for multivariate analysis. Data were autoscaled and, if necessary, variables were normalized prior to the analyses. The data matrix $\mathbf{X}$ was analyzed by principal component analysis (PCA) and partial least square discriminant analysis (PLS-DA) models. The multivariate analyses were performed by SIMCA-P v.11.5 (Umetrics, Umea, Sweden). The validation of models were done by leave-one-out cross validation and given in terms of statistical $\mathrm{Q}^{2}$ measure as the prediction ability of the corresponding model. PLS-DA analyses were performed after constructing a general PCA model of data.

\section{Results and Discussion}

The concentrations of phenolic compounds (expressed in $\mathrm{mg} / \mathrm{kg}$ olive oil) and quality parameters of olive oil samples for two geographical origins of 2005 and 2006 harvest years are given in Table 2. TPC significantly differs in 2006 with respect to growing region. The PV parameter reflects the processing and storage conditions. PV values of samples are below 20 mequiv $\mathrm{O}_{2} \mathrm{~kg}^{-1}$ except three northern oils of 2005 [Edremit (Ed), Burhaniye (Bur) and Gomec (Gom)] and one southern oil of 2005 [Kocarli (Koc)], which had PVs between 23 and 25 mequi$\mathrm{v} \mathrm{O}_{2} \mathrm{~kg}^{-1}$. No differences were observed between north and south samples with respect to PV values. No significant difference was observed in terms of color parameters, either. These quality parameters were included in the chemometric analysis along with phenolic compounds due to the possible multivariate interactions.

HPLC-DAD analysis allowed the quantification of simple phenols, phenolic acids and flavonoids. Representative HPLC chromatograms of the commercial EVOOs in 2005 and 2006 harvest years are shown in Fig. 2a, b, respectively (at $280 \mathrm{~nm}$ ). Ayvalik and Havran are north, Aydin and Bayindir are south Aegean oils. Individual phenols varied depending on the geographical region for two harvest years, with statistically significant differences in some compounds. For the first harvest year, the main differences in the phenolic fraction among oils of two growing areas were different contents of tyrosol, hydroxytyrosol to tyrosol ratio (hyt/tyr), vanillin, peak 15, and luteolin. Tyrosol were higher in olive oils from south Aegean than those from north Aegean, which had higher vanillin and luteolin contents. In the second harvest year, except TPC, qualitative parameters (PV and color) showed no differences statistically. TPC values were observed as higher in south Aegean oils. Significant differences were observed in a wide number of phenolic compounds (hydroxytyrosol, tyrosol, syringic acid, $p$-coumaric acid, $m$-coumaric acid, cinnamic acid and apigenin). Tyrosol, $p$-coumaric acid, cinnamic acid and apigenin were found higher in the south oils, whereas hydroxytyrosol and syringic acid were relatively higher in the north oils. Since the method for phenolic identification was adopted from Brenes et al. [21, 22], some unidentified peaks were matched with some of the secoiridoids and lignans found in their studies. Peak 11 at around $44 \mathrm{~min}$. can be attributed to dialdehydic form of elenolic acid linked to tyrosol, whereas the unidentified peak 13 appeared before cinnamic acid (retention time at around $49.5 \mathrm{~min}$.) can be considered as oleuropein aglycon. Peak 16 between luteolin and apigenin might be identified as ligstroside aglycon. The peaks 11 and 16 were quantified in terms of tyrosol; the peaks 12 and 13 were expressed in terms of oleuropein.

In the north Aegean coast area, the Ayvalik variety is the dominant olive for oil production (It is also known as Edremit). On the other hand, Memecik is the olive cultivar mostly used for oil production in the south Aegean. Therefore, the commercial olive oil samples of different regions also reflect the differences in these varieties. Geographical differences of products depend on several parameters like variety, soil, expertise, and culture. The applications for the geographical indication labeling of olive oil have increased recently in Europe and also in Turkey (Turkish Patent Institute, http://www.turkpatent.gov.tr, 2011). Therefore, it is becoming more important to show the discrimination among the products of different origins. Vanillin and syringic acid are two phenols that seemed to be characteristic of north oils. Besides, the peak 13, which is considered to be oleuropein aglycon was consistently higher in north oils for 2 years. It was observed that south olive oils contained higher amounts of tyrosol in two consecutive years. Similarly, cinnamic acid, even though it was absent in north oils and present in very small amounts in south oils in 2005, was present in significantly higher amounts in south oils in the second harvest year, too. The same trend was observed for $p$-coumaric acid and apigenin in the south oils.

Some phenolic compounds were observed as yeardependent. Syringic acid was absent in all oil samples in 2005 harvest year. In the subsequent year, concentration of it was observed as higher in north olive oils. Vanillin, on the other hand, was higher in north oils in 2005, whereas it was detected in very low amounts in 2006. $m$-Coumaric acid was absent in 2005, and it was detected in very low amounts, without any significant differences among olive oil samples. Ferulic acid was detected in higher concentrations in 2006. In another study, differences in the composition of olive oil with respect to harvest year were shown [23]. In that study, the changes in phenolics in different harvest seasons and crop years, depending on the 
Table 2 Comparison of chemical parameters and phenolic contents of commercial EVOOs with respect to geographical origin $($ mean $\pm \mathrm{SD})$

a, b Different letters within the same row indicate a significant difference $(p<0.05)$ between North and South

${ }^{c}$ For the explanation of phenolic abbreviations, see Fig. 2

\begin{tabular}{|c|c|c|c|c|}
\hline & \multicolumn{2}{|l|}{2005} & \multicolumn{2}{|l|}{2006} \\
\hline & North & South & North & South \\
\hline $\mathrm{Hyt}^{\mathrm{c}}$ & $3.16 \pm 1.58$ & $4.27 \pm 2.65$ & $7.36 \pm 6.7^{\mathrm{b}}$ & $3.89 \pm 2.57^{\mathrm{a}}$ \\
\hline Tyr & $1.70 \pm 0.91^{\mathrm{a}}$ & $6.96 \pm 4.37^{\mathrm{b}}$ & $4.92 \pm 5.05^{\mathrm{a}}$ & $10.67 \pm 7.44^{\mathrm{b}}$ \\
\hline Hyt/Tyr & $2.04 \pm 0.61^{\mathrm{b}}$ & $0.57 \pm 0.35^{\mathrm{a}}$ & $1.56 \pm 0.57^{\mathrm{b}}$ & $0.52 \pm 0.37^{\mathrm{a}}$ \\
\hline Hpha & $0.17 \pm 0.097$ & $0.12 \pm 0.18$ & $0.22 \pm 0.19$ & $0.11 \pm 0.10$ \\
\hline $\mathrm{Ca}$ & $0.003 \pm 0.01$ & nd & $0.04 \pm 0.04$ & $0.05 \pm 0.04$ \\
\hline Va & $0.06 \pm 0.05$ & $0.07 \pm 0.07$ & $0.17 \pm 0.15$ & $0.10 \pm 0.10$ \\
\hline Sya & nd & nd & $0.36 \pm 0.2^{\mathrm{b}}$ & $0.16 \pm 0.1^{\mathrm{a}}$ \\
\hline Val & $0.35 \pm 0.12^{\mathrm{b}}$ & $0.16 \pm 0.06^{\mathrm{a}}$ & $0.02 \pm 0.02$ & $0.01 \pm 0.02$ \\
\hline Pco & $0.1 \pm 0.08$ & $0.14 \pm 0.16$ & $0.32 \pm 0.21^{\mathrm{a}}$ & $0.69 \pm 0.46^{\mathrm{b}}$ \\
\hline $\mathrm{Fa}$ & $0.03 \pm 0.03$ & $0.06 \pm 0.09$ & $0.15 \pm 0.14$ & $0.26 \pm 0.14$ \\
\hline Mco & nd & nd & $0.02 \pm 0.01^{\mathrm{a}}$ & $0.04 \pm 0.02^{\mathrm{b}}$ \\
\hline Peak 11 & $0.16 \pm 0.13$ & $0.09 \pm 0.14$ & $0.33 \pm 0.14$ & $0.16 \pm 0.19$ \\
\hline Peak 12 & $0.24 \pm 0.15$ & $0.30 \pm 0.36$ & $0.58 \pm 0.20$ & $0.92 \pm 0.44$ \\
\hline Peak 13 & $3.25 \pm 2.02^{\mathrm{b}}$ & $1.02 \pm 1.41^{\mathrm{a}}$ & $6.63 \pm 2.72^{\mathrm{b}}$ & $3.21 \pm 1.17^{\mathrm{a}}$ \\
\hline Cina & nd & $0.13 \pm 0.09$ & $0.06 \pm 0.05^{\mathrm{a}}$ & $0.66 \pm 0.21^{\mathrm{b}}$ \\
\hline Lut & $1.66 \pm 0.63^{\mathrm{b}}$ & $0.82 \pm 0.75^{\mathrm{a}}$ & $1.13 \pm 1.05$ & $1.26 \pm 0.9$ \\
\hline Peak 16 & $0.73 \pm 0.47$ & $0.56 \pm 0.74$ & $0.36 \pm 0.46$ & $0.40 \pm 0.34$ \\
\hline Apg & $0.77 \pm 0.85$ & $1.1 \pm 0.8$ & $1.56 \pm 0.83^{\mathrm{a}}$ & $2.64 \pm 1.29^{\mathrm{b}}$ \\
\hline PV & $17.07 \pm 6.4$ & $17.88 \pm 7.32$ & $11.44 \pm 2.82$ & $11.88 \pm 2.19$ \\
\hline $\mathrm{L}^{*}$ & $23.45 \pm 1.11$ & $24.33 \pm 0.93$ & $23.81 \pm 0.81$ & $23.72 \pm 1.03$ \\
\hline$a^{*}$ & $-0.22 \pm 0.84$ & $-0.81 \pm 0.85$ & $-0.69 \pm 0.6$ & $-0.54 \pm 0.73$ \\
\hline $\mathrm{b}^{*}$ & $11.39 \pm 1.46$ & $12.53 \pm 1.01$ & $11.48 \pm 1.04$ & $11.29 \pm 1.54$ \\
\hline TPC & $202.18 \pm 65.36$ & $201.74 \pm 72.90$ & $230.71 \pm 55.3^{\mathrm{a}}$ & $287.35 \pm 58.2^{\mathrm{b}}$ \\
\hline
\end{tabular}

year's weather changes were emphasized. Significant differences were observed in vanillic acid, vanillin, secoiridoid derivatives and flavonoids (luteolin, apigenin).

Figure $3 \mathrm{a}$ is the scatter plot of the first two principal components of PLS-DA model of the data including phenolics and quality variables. The four classes were predefined as north and south oils of 2005 and north and south oils of 2006. The model has five components and $\mathrm{Q}^{2}$ of 0.662. The north olive oils are accumulated in the upper part of the control ellipse, whereas the south olive oil samples are in the lower part. The 2005 oils are on the right of the figure, and the 2006 oils are on the left. The groupings in the score plot are with respect to both geography and harvest year. Figure $3 \mathrm{~b}$ shows the distribution of variables on the loading plot of the model. The location of variables in the loading plot explains the reasons why certain observations form clusters in the score plot. Cinnamic acid (Cina) and tyrosol (Tyr) are on the same side with 2006-south oils, which have higher amounts of these compounds. On the other hand, vanillin ( $\mathrm{Val}$ ) is on the same side as the 2005-north oils and syringic acid (Sya) is on the left upper part as the 2006-north oils. Peak 13 is located in the upper part of the control ellipse, where north oils also appear.
In another work, in which Turkish olive oils of different Turkish varieties of Aegean region were studied, the same conclusions were reached for extra virgin oils of the typical southern Aegean oils, such as memecik, erkence and the northern Aegean oils such as ayvalik and gemlik [11]. In that study, six olive varieties were harvested in controlled groves in only two locations and the oils were obtained in a batch, laboratory-scale olive mill. In this present work, on the other hand, the oil samples came from continuous olive mills all around Aegean coast. Despite the different production experiences, finding very similar phenolic distributions confirms the differences between the extra virgin olive oil samples from these two geographical areas.

According to the findings of a study on Turkish olive oils [20], higher amounts of tyrosol, p-coumaric acid and apigenin were found in memecik oils (southern Aegean), whereas higher amounts of hydroxytyrosol were determined in ayvalik oils (northern Aegean). Similarly, in our study, hydroxytyrosol content in the northern oils in 2006 was significantly higher (Table 2). However, it might be difficult to state that hydroxytyrosol content of ayvalik or northern oils always follow this trend. It shows a great variability within the same region or for the same cultivar. In 2005 and 2006 samples of north oils, the range for 
Fig. 2 HPLC chromatograms of the phenolic extract of EVOOs of 2005 (a) and of 2006 (b) at $280 \mathrm{~nm}$ : (IS) gallic acid; (1) hydroxytyrosol (Hyt); (2) tyrosol (Tyr); (3)

4hydroxyphenylacetic acid (Hpha); (4) caffeic acid (Ca); (5) vanillic acid (Va); (6) vanillin (Val); (7) syringic acid (Sya); (8) $p$-coumaric acid (Pcoa); (9) ferulic acid (Fa); (10) $m$-coumaric acid (Mcoa); (11) peak $11 ;(12)$ peak 12 ; (13) peak 13; (14) cinnamic acid (Cina); (15) luteolin (Lut); (16) peak 16; (17) apigenin (Apg)
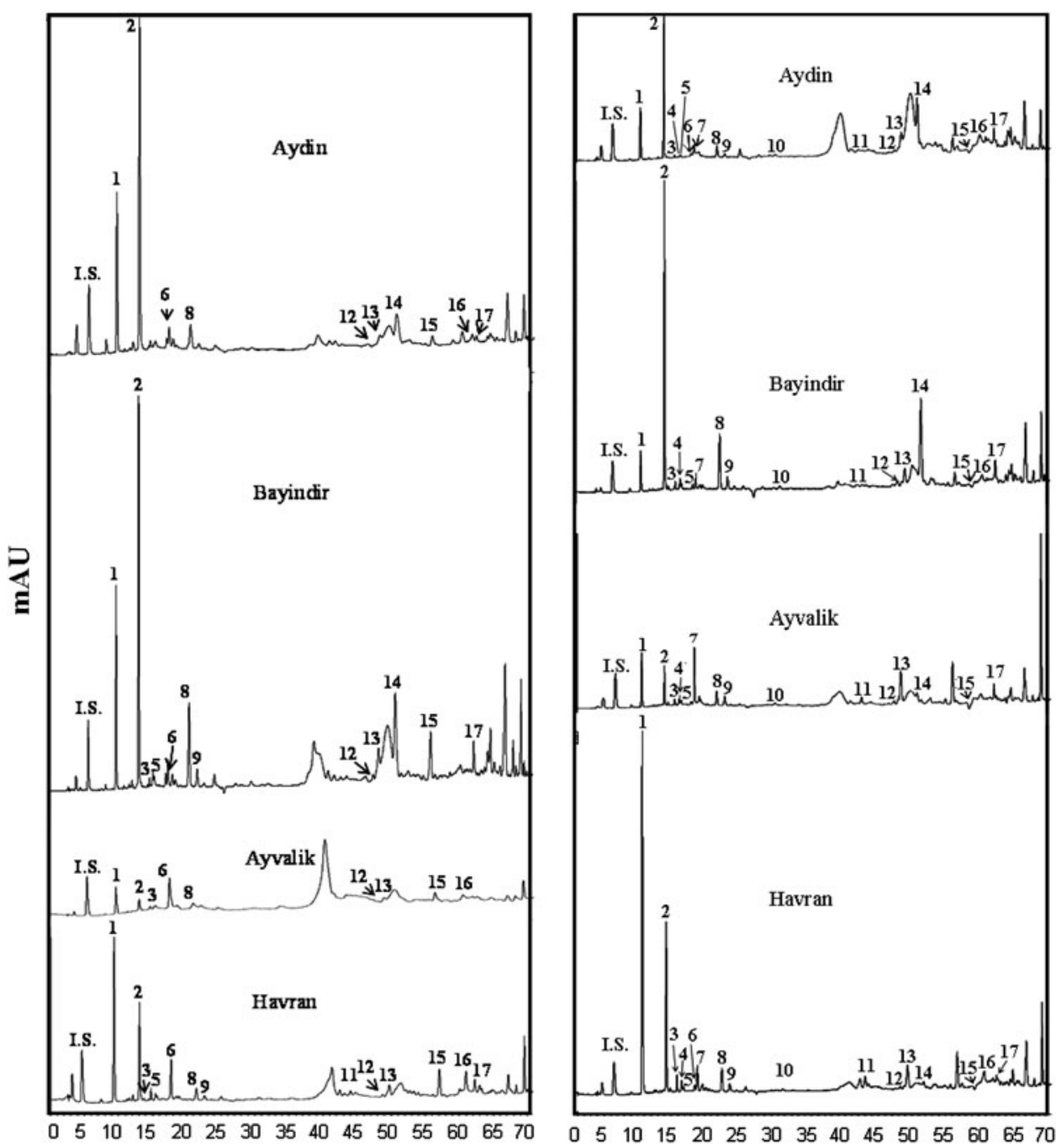

(a)
Time (minute) (b) hydroxytyrosol concentrations were [1.13-7.67] and [1.68-18.57] $\mathrm{mg} \mathrm{kg}^{-1}$, respectively. On the other hand, the hyt/tyr ratio of northern oils changed in a more robust manner as [0.64-3.40] and [0.87-2.44] for the same harvest years. Multivariate analysis shows that the ratio of hydroxytyrosol to tyrosol (hyt/tyr), rather than hydroxytyrosol itself, is a better discriminant for the northern oils. When the oils of both harvest years are compared, the northern oils have a significantly higher hyt/tyr ratio $(P<0.05)$. The PLS-DA loading plot (Fig. 3b) shows that this particular ratio appears in the right upper part. It is the same part in Fig. 3a, where the north olive oils are located. Tsimidou et al. [24] stated that hyt/tyr parameter could account for the oxidative stability of olive oil24. Therefore, inclusion of the ratio of these simple phenols in multivariate analysis of olive oils may enhance the classification and be helpful in the explanation of oxidative study results.
In PLS models, the most relevant variables are listed in terms of their VIP values (Variable Importance in Projection). The terms with VIP of 1.0 or larger are considered to be the most relevant variables in explaining the response (Y matrix). The variables of the PLS-DA model of olive oil data with VIP values greater than 1.0 are syringic acid, hyt/ tyr, cinnamic acid, peak 13, luteolin, peak 16, vanillin, tyrosol, peak 11, and $p$-coumaric acid in descending order.

\section{Conclusion}

In this study, phenolic acids, simple phenols and flavonoid compounds of extra virgin olive oils from different regions were quantified by HPLC. As a result of multivariate analysis of the phenolic data, it was shown that oil samples of different regions show differences in some of the 


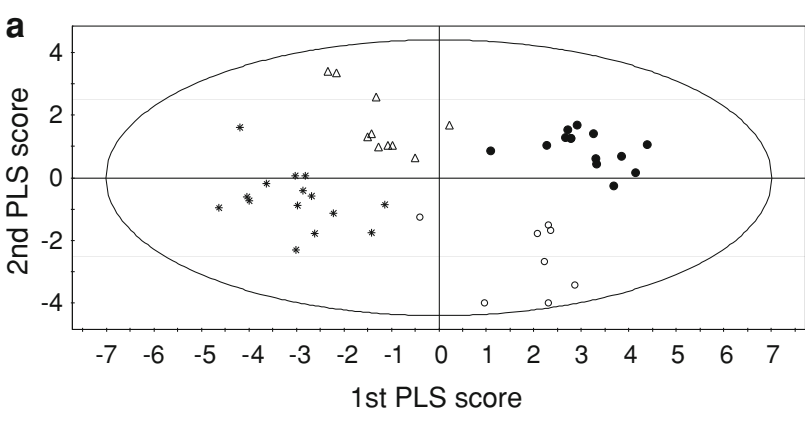

- Class 1 - Class $2 \triangle$ Class $3 *$ Class 4 SIMCA-P 11.5 - 3/30/2010 3:04:16 PM

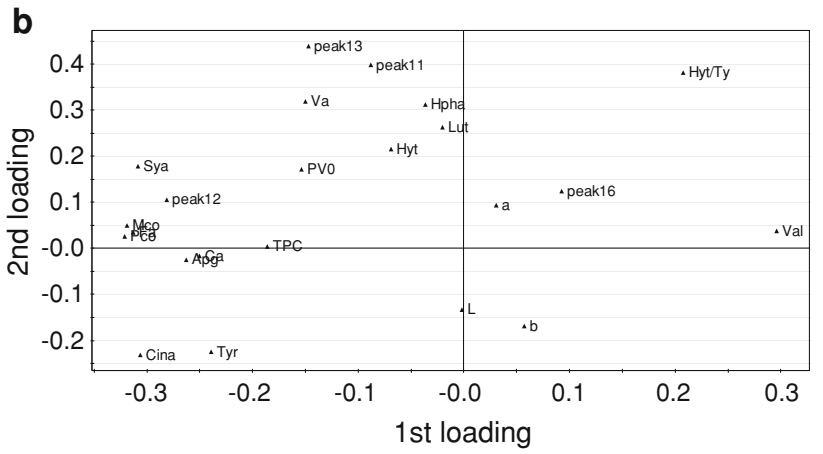

SIMCA-P 11.5 - 3/30/2010 3:31:25 PM

Fig. 3 a The score plot of PLS-DA model of olive oil data: Class 1 (closed circles): North 2005; Class 2 (open circles): South 2005; Class 3 (open triangles): North 2006; Class 4 (asterisks): South 2006. b The loading plot of PLS-DA model of olive oil data

phenolic compounds. The characteristics of the northern Aegean olive oil samples, from the ayvalik variety, are a high hydroxytyrosol to tyrosol ratio, and depending on the harvest year, higher vanillin and syringic acid concentrations. The olive oils of the southern Aegean part of Turkey have phenolic profiles of higher tyrosol, $p$-coumaric acid, cinnamic acid and apigenin concentrations. These characteristics can be used as the typical parameters of the extra virgin olive oils from coastal Aegean regions of Turkey.

Acknowledgments This study was financed by the scientific research fund of the Izmir Institute of Technology (IYTE2005-39).

\section{References}

1. Tuck KL, Hayball PJ (2002) Major phenolic compounds in olive oil: metabolism and health effects. J Nutr Biochem 13:636-644

2. Miles EA, Zoubouli P, Calder PC, Phil D (2005) Differential antiinflammatory effects of phenolic compounds from extra virgin olive oil identified in human whole blood cultures. Nutrition 21:389-394

3. Visioli F, Poli A, Galli C (2002) Antioxidant and other biological activities of phenols from olives and olive oil. Med Res Rev 22:65-75

4. Perez-Jimenez F, Ruano J, Perez-Martinez P, Lopez-Segura F, Lopez-Miranda J (2007) The influence of olive oil on human health: not a question of fat alone. Mol Nut Food Res 51:1199-1208

5. Velasco J, Dobarganes C (2002) Oxidative stability of virgin olive oil. Eur J Lipid Sci Technol 104:661-676

6. Gallina-Toshi T, Cerretani L, Bendini A, Bonoli-Carbognin M, Lercker G (2005) Oxidative stability and phenolic content of virgin olive oil: An analytical approach by traditional and high resolution techniques. J Sep Sci 28:859-870

7. Servili M, Montedoro G (2002) Contribution of phenolic compounds to virgin olive oil quality. Eur J Lipid Sci Technol 104:602-613

8. Cerretani L, Salvador MD, Bendini A, Fregapane G (2008) Relationship between sensory evaluation performed by Italian and Spanish officials panels and volatile and phenolic profiles of virgin olive oils. Chem Percept 1:258-267

9. Petrakis PV, Agiomyrgianaki A, Christophoridou S, Spyros A, Dais P (2008) Geographical characterization of Greek virgin olive oils (cv. koroneiki) using ${ }^{1} \mathrm{H}$ and ${ }^{31} \mathrm{P}$ NMR and classification binary trees. J Agric Food Chem 56:3200-3207

10. Lerma-Garcia MJ, Lantano C, Chiavaro E, Cerretani L, HerreroMartinez JM, Simo-Alfonso EF (2009) Classification of extra virgin olive oils according to their biological origin using phenolic compound profiles obtained by capillary electrochromatography. Food Res Int 42:1446-1452

11. Ocakoglu D, Tokatli F, Ozen B, Korel F (2009) Distribution of simple phenols, phenolic acids, and flavonoids in Turkish monovarietal extra virgin olive oils for two harvest years. Food Chem 113:401-410

12. Ouni Y, Taamalli A, Gomez-Caravaca AM, Segura-Carretero A, Fernandez-Gutierrez A, Zarrouk M (2011) Characterization and quantification of phenolic compounds of extra virgin olive oils according to their geographical origin by a rapid resolutive LC-ESI-TOF MS method. Food Chem 127:1263-1267

13. Tanilgan K, Ozcan MM, Unver A (2007) Physical and chemical characteristics of Turkish olive (Olea europea L.) varieties and their oils. Grasas Aceities 58:142-147

14. Gurdeniz G, Ozen B, Tokatli F (2008) Classification of Turkish olive oils with respect to cultivar, geographic origin and harvest year, using fatty acid profile and mid-IR spectroscopy. Eur Food Res Technol 227:1275-1281

15. Ogutcu M, Mendes M, Yilmaz E (2008) Sensorial and physicochemical characterization of virgin olive oils produced in Canakkale. J Am Oil Chem Soc 85:441-456

16. Diraman H, Dibeklioglu H (2009) Characterization of Turkish virgin olive oils produced from early harvest olives. J Am Oil Chem Soc 86:663-674

17. Kiralan M, Bayrak A, Ozkaya M (2009) Oxidation stability of virgin olive oils from some important cultivars in east Mediterranean area in Turkey. J Am Oil Chem Soc 86:247-252

18. Ogutcu M, Yilmaz E (2009) Comparison of the virgin olive oils produced in different regions of Turkey. J Sens Stud 24:332-353

19. Ilyasoglu H, Ozcelik B, Van Hoed V, Verhe R (2010) Characterization of Aegean olive oils by their minor compounds. J Am Oil Chem Soc 87:627-636

20. Montedoro G, Servili M, Baldioli M, Miniati E (1992) Simple and hydrolysable phenolic compounds in virgin olive oil. 1 . Their extraction, separation, and quantitative and semi quantitative evaluation by HPLC. J Agric Food Chem 40:1571-1578

21. Brenes M, Garcia A, Garcia P, Rios JJ, Garrido A (1999) Phenolic compounds in Spanish olive oils. J Agric Food Chem 47:3535-3540

22. Brenes M, Hidalgo FJ, Garcia A, Rios JJ, Garcia P, Zamora R, Garrido A (2000) Pinoresinol and 1-acetoxypinoresinol, two new phenolic compounds identified in olive oil. J Am Oil Chem Soc 77:715-720 
23. Morello JR, Romero MP, Motilva MJ (2006) Influence of seasonal conditions on the composition and quality parameters of monovarietal virgin olive oils. J Am Oil Chem Soc 83:683-690
24. Tsimidou M, Papadopoulos G, Boskou D (1992) Phenolic compounds and stability of virgin olive oil-Part I. Food Chem 45:141-144 